\title{
Glaucoma drainage devices; past, present, and future
}

\author{
K S Lim, B D S Allan, A W Lloyd, A Muir, P T Khaw
}

Glaucoma filtration surgery (GFS) has been shown to be more effective at preventing disease progression than other primary treatment modalities in open angle glaucoma. ${ }^{12}$ If it were possible to avoid complications associated with poor flow control, primary GFS would probably be offered more widely.

Trabeculectomy, the procedure of choice in conventional GFS, has remained essentially unchanged for over a quarter of a century. Local control over wound healing with antimetabolite agents such as 5-fluorouracil and mitomycin $\mathrm{C}$ has improved the prognosis for cases with high risk of filtration failure; but flow control remains inexact despite the introduction of a variety of suture adjustment techniques.

Glaucoma drainage devices (GDDs) have the potential to regulate flow consistently, eliminating hypotony after GFS. Design, material, and manufacturing deficiencies have left this potential unfulfilled in existing GDDs, all of which exhibit problems with poor flow control and suboptimal tissue compatibility. The role of GDDs in contemporary GFS remains poorly defined, but possibilities offered by new biomaterials and the goal of accurate flow control have stimulated considerable recent interest in GDD development. This review traces the progress of GDD design through to the present and beyond.

\section{Early glaucoma drainage devices}

In 1906, horse hair ${ }^{3}$ was placed through a corneal paracentesis in an attempt to drain a hypopyon externally. The same technique was later used to treat two patients with painful absolute glaucoma. ${ }^{4}$ Sporadic attempts using implants to shunt aqueous to a variety of unconventional sites, including the vortex veins ${ }^{5}$ and the nasolacrimal duct, ${ }^{6}$ have since been reported. Results were generally unfavourable or too poorly documented to evaluate, and attention has focused on devices shunting aqueous fluid to the subconjunctival space as with conventional GFS.

The first translimbal GDD, reported by Zorab ${ }^{7}$ in 1912, was silk thread used as a seton to aid drainage of anterior chamber fluid to the subconjunctival space. This was followed by similar use of gold, ${ }^{8}$ tantalum, ${ }^{9}$ and platinum thread/wire. ${ }^{10}$ Results were universally poor as these and other early translimbal setons (Table 1) did not address lack of flow control and hypotony associated with full thickness (unguarded) GFS, and added a foreign body chronic inflammatory stimulus. Simple translimbal tube devices ${ }^{16}{ }^{17}$ were similarly unsuccessful, with high rates of early filtration failure.

Translimbal drainage implants, or anterior GDDs, were implanted with the intention of preventing filtration failure by maintaining patency of a drainage fistula or sclerostomy. Anterior GDDs failed to improve filtration failure rates in comparison with conventional GFS, but it took almost half a century for investigators to begin to rationalise this lack of success.

In 1969 , Molteno ${ }^{18}$ hypothesised that filtration failure was primarily attributable to subconjunctival fibrosis, with fistula closure occurring as a secondary event. This was later confirmed in histological studies of animal models of GFS. ${ }^{32}$ Realising that simple anterior GDDs would have little impact on this process, Molteno launched the concept of tube and plate GDDs, in which aqueous fluid is

Table 1 Developments of glaucoma drainage devices

\begin{tabular}{|c|c|c|c|c|c|c|}
\hline Year & Investigator & Type & Material & Method & Flow control & Drainage site \\
\hline 1907 & Rollet $^{4}$ & seton & Horse hair & Paracentesis & None & External cornea \\
\hline 1912 & Zorab $^{7}$ & seton & Silk thread & Translimbal & None & Anterior subconjunctival \\
\hline 1925 & Stefansson ${ }^{8}$ & seton/tube & Gold & Translimbal & None & Anterior subconjunctival \\
\hline 1934 & Row $^{11}$ & seton & Platinum & Cyclodialysis & None & Suprachoroidal \\
\hline 1940 & Troncoso $^{12}$ & seton & Magnesium & Cyclodialysis & None & Suprachoroidal \\
\hline 1942 & Gibson $^{13}$ & tube & Lacrimal canaliculus & Transcleral & None & Anterior subconjunctival \\
\hline 1949 & Bick $^{9}$ & seton/tube & Tantalum & Cyclodialysis & None & Suprachoroidal \\
\hline 1951 & Muldoon $^{10}$ & seton & Platinum & Translimbal & None & Anterior subconjunctival \\
\hline 1952 & Losche $^{14}$ & tube & Supramid & Cyclodialysis & None & Suprachoroidal \\
\hline 1955 & $\mathrm{Bietti}^{15}$ & tube & Polyethylene & Cyclodialysis & None & Suprachoroidal \\
\hline 1958 & La Rocca ${ }^{16}$ & tube & Polyvinyl & Translimbal & None & Anterior subconjunctival \\
\hline 1960 & Ellis $^{17}$ & tube & Silicone & Translimbal & None & Anterior subconjunctival \\
\hline 1967 & Mascati $^{6}$ & tube & Plastic & Translimbal & None & Lacrimal sac \\
\hline 1969 & Molteno $^{18}$ & tube and plate & Acrylic & Translimbal & None & Anterior subconjunctival \\
\hline 1974 & Lee and Wong ${ }^{5}$ & tube & Collagen & Translimbal & None & Vortex vein \\
\hline 1976 & Krupin $^{19}$ & tube & Silicone and supramid & Translimbal & Slit valve & Anterior subconjunctival \\
\hline 1979 & Honrubia $^{20}$ & tube & Silicone & Translimbal & None & Anterior subconjunctival \\
\hline 1982 & Schocket ${ }^{21}$ & tube and band & Silicone & Translimbal & None & Posterior subconjunctiva \\
\hline 1985 & White $\mathrm{e}^{22}$ & tube and plate & Silicone & Silicone & Valve and pump & Posterior subconjunctiva \\
\hline 1986 & Joseph $^{23}$ & tube and band & Silicone & Translimbal & Slit valve & Posterior subconjunctiva \\
\hline 1990 & Krupin $^{24}$ & tube and plate & Silicone & Translimbal & Slit valve & Posterior subconjunctiva \\
\hline 1990 & Baerveldt ${ }^{25}$ & tube and plate & Silicone & Translimbal & None & Posterior subconjunctiva \\
\hline 1993 & Ahmed $^{26}$ & tube and plate & Silicone and polypropylene & Translimbal & Venturi valve & Posterior subconjunctiva \\
\hline 1995 & OptiMed ${ }^{27}$ & tube and plate & Silicone and PMMA & Translimbal & Microtubules & Posterior subconjunctiva \\
\hline 1995 & Smith $^{28}$ & seton & Hydrogel & Translimbal & None & Intrascleral \\
\hline 1996 & Pandya $^{29}$ & tube and plate & Silicone and hydroxylapatite & Translimbal & None & Posterior subconjunctiva \\
\hline 1997 & Glovinsky and Belkin ${ }^{30}$ & tube & Stainless steel & Translimbal & None & Anterior subconjunctival \\
\hline 1997 & Helies $^{31}$ & artificial meshwork & PTFE & Transcleral & None & Anterior subconjunctival \\
\hline
\end{tabular}


Table 2 Contemporary glaucoma drainage devices (GDDs)

\begin{tabular}{|c|c|c|c|c|}
\hline$G D D s$ & $\begin{array}{l}\text { Year of } \\
\text { introduction }\end{array}$ & Tube diameter/material & Plate size/material & Resistance mechanism \\
\hline Molteno & 1979 & $\begin{array}{l}0.63 \mathrm{~mm} \text { OD } \\
0.30 \mathrm{~mm} \text { ID } \\
\text { Silicone }\end{array}$ & $135 \mathrm{~mm}^{2}$ polypropylene & None \\
\hline Baerveldt & 1990 & $\begin{array}{l}0.63 \mathrm{~mm} \text { OD } \\
0.30 \mathrm{~mm} \text { ID } \\
\text { Silicone }\end{array}$ & $200,250,350,425,500 \mathrm{~mm}^{2}$ silicone & None \\
\hline Krupin with disc & 1990 & $\begin{array}{l}0.58 \mathrm{~mm} \text { OD } \\
0.38 \mathrm{~mm} \text { ID } \\
\text { Silicone }\end{array}$ & $180 \mathrm{~mm}^{2}$ silicone & Slit valve \\
\hline Ahmed & 1993 & $\begin{array}{l}0.63 \mathrm{~mm} \text { OD } \\
0.30 \mathrm{~mm} \text { ID } \\
\text { Silicone }\end{array}$ & $185 \mathrm{~mm}^{2}$ polypropylene with silicone valve & Venturi valve \\
\hline Optimed Model-1014 & 1995 & $\begin{array}{l}0.56 \mathrm{~mm} \text { OD } \\
0.30 \mathrm{~mm} \text { ID } \\
\text { Silicone }\end{array}$ & $140 \mathrm{~mm}^{2}$ silicone with PMMA matrix & Microtubules \\
\hline
\end{tabular}

$\mathrm{OD}=$ outside diameter.

ID $=$ inside diameter.

shunted to a plate device designed to maintain patency of a subconjunctival filtration reservoir in the face of continuing subconjunctival fibrosis. Although confined to use in complex cases by the advent of trabeculectomy and relatively successful conventional guarded GFS, ${ }^{34}$ these were the first GDDs to gain widespread acceptance and the Molteno tube remains the benchmark against which other tube devices are compared.

\section{Contemporary GDDs}

Tube and plate devices still dominate the contemporary GDD market. Prominent examples, in chronological order, are the Molteno, Krupin, Baerveldt, Ahmed, and OptiMed GDDs (Figs 1-5). Molteno ${ }^{35}$ moved the plate element of his early devices posteriorly away from the limbus to avoid problems with dellen formation and poor filtration associated with pre-existing anterior conjunctival scarring. Posterior placement beneath Tenon's capsule was also thought to improve protection from extrusion. ${ }^{36}$ Subsequent tube and plate GDDs share the essential design concept of posterior filtration via a tube in the anterior chamber to a plate element secured beneath Tenon's capsule, but differ in plate design and their provision for a flow control mechanism to protect from early postoperative hypotony (Table 2 ).

\section{Evaluation}

Most GDDs have been developed in a virtual publication vacuum, with little available data to substantiate manufacturers' claims for flow performance ${ }^{37}$ or biocompatibility. Clinical data are largely restricted to uncontrolled retrospective case series ${ }^{38}$ with variable follow up and differing definitions of surgical success. Evaluation is further complicated by the heterogeneity of inclusion criteria. Series included a variable proportion of complex cases, neovascular glaucoma in particular, with a predetermined high risk of filtration failure. Existing results are summarised in Table 3. Overall success rates, in terms of IOP control, appear similar between devices, with a reasonably high proportion of cases achieving a final IOP in the target range at 1 year after surgery. Half to two thirds of these cases still require glaucoma medications, however, and target IOPs in the low teens ( $\leqslant 16 \mathrm{~mm} \mathrm{Hg}$ ) may be more realistic in terms of preventing disease progression than commonly adopted target levels ( $\leqslant 21$ or $22 \mathrm{~mm} \mathrm{Hg}$ ), particularly where glaucomatous optic neuropathy is already advanced. ${ }^{49} 50$

Another important caveat concerns attrition rates, or continued increments in the proportion of filtration failures with lengthening postoperative follow up. Again, evaluation is difficult, with few series including either long term data or survival analysis. Mills et al ${ }^{39}$ (Table 3)
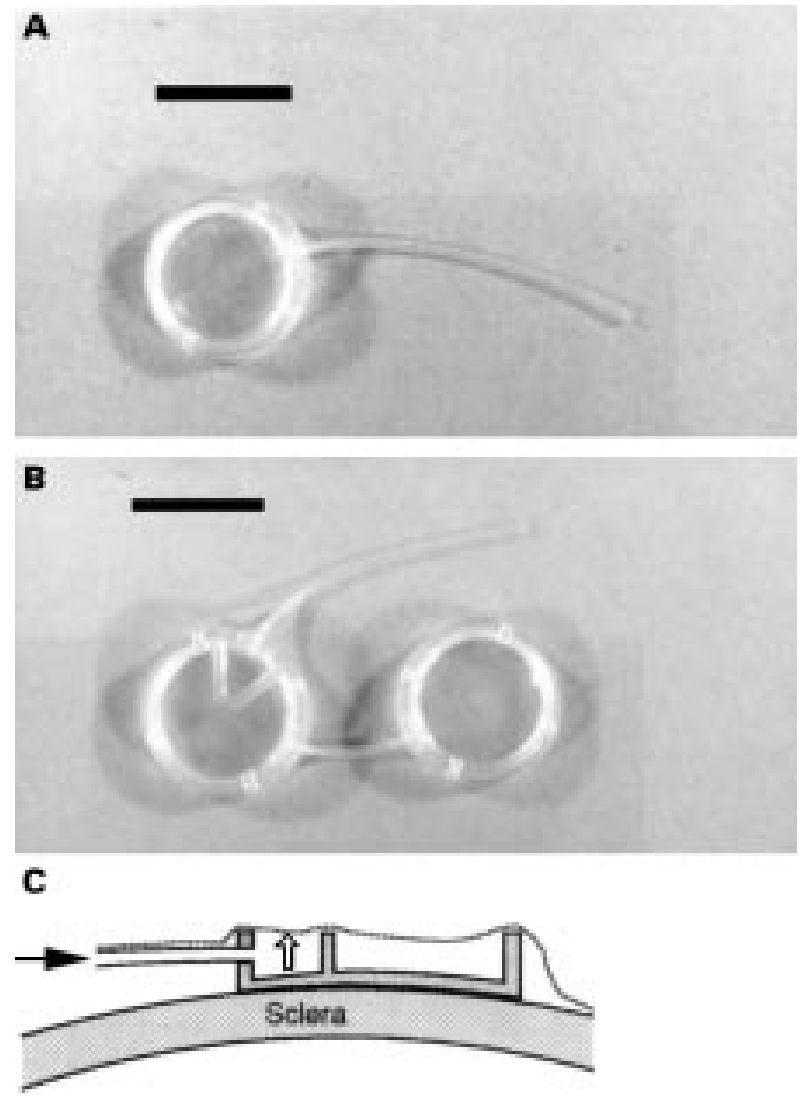

Figure 1 (A) Single plate Molteno implant (scale bar $=1 \mathrm{~cm}$ ). (B) Dual chamber double plate Molteno implant (scale bar =1 cm). $(C)$ Schematic drawing of the resistance mechanism of a dual chamber single plate Molteno implant. The thin V-shaped ridge (see B) has the same height as the circumferential rim of the polypropylene plate. The top surface of the plate is divided into one smaller and one larger chamber by the apposition of the overlying conjunctival and Tenon's layers (dotted line). Aqueous flows (black arrow) into the smaller proximal chamber until sufficient pressure is achieved within the chamber to lift (white arrow) the overlying conjunctival layer to allow free drainage.

reported a $10 \%$ failure rate per postoperative year in a series including longer term follow up for single and double plate Molteno tubes. Extrapolating from this, it would appear that most GDDs have a functional lifespan of less than 5 years before failure though fibrous encapsulation.

\section{Complication mechanisms}

Clinical series reporting GDD procedures are characterised by frequent problems in addition to filtration failure (Table 4), with one or more complication affecting around $60-70 \%$ of all patients. ${ }^{41}{ }^{46}$ While partly attributable to the 


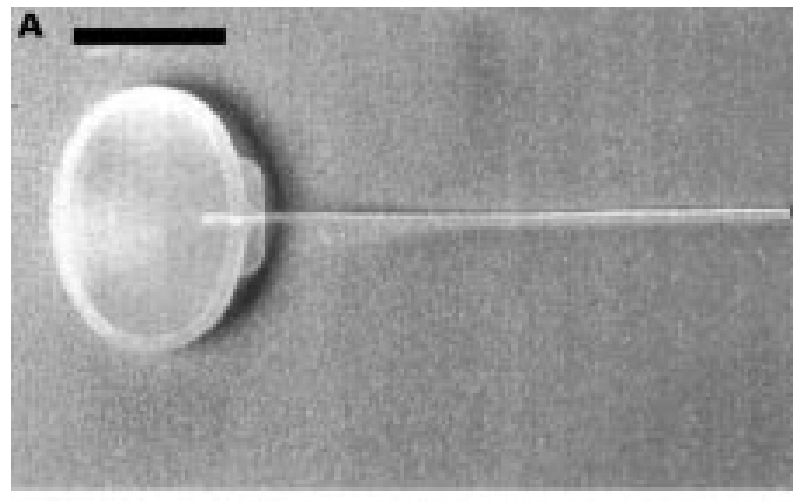

B
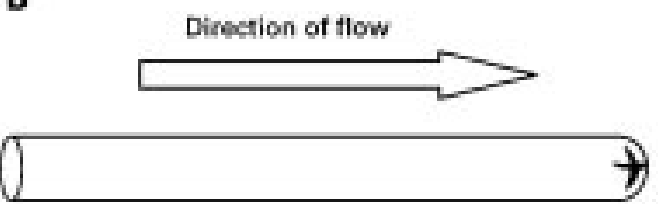

Figure 2 (A) The Krupin valve with disc, slit valve is situated at the plate end of the tube (scale bar $=1 \mathrm{~cm}$ ). (B) A schematic drawing of the Krupin slit valve, showing the crossed slit elements.

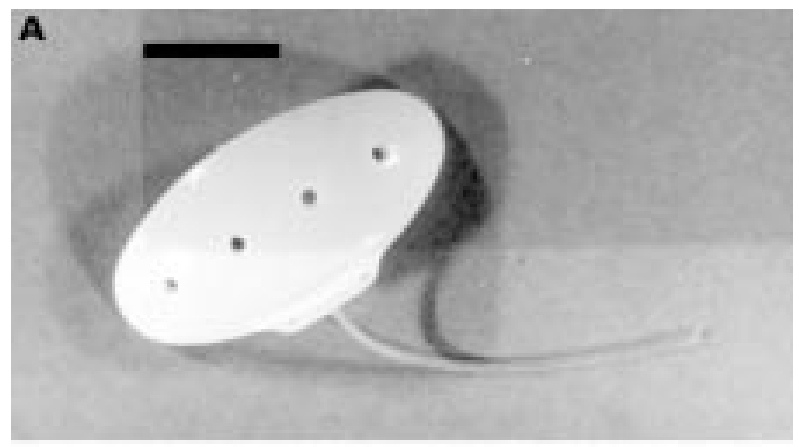

B

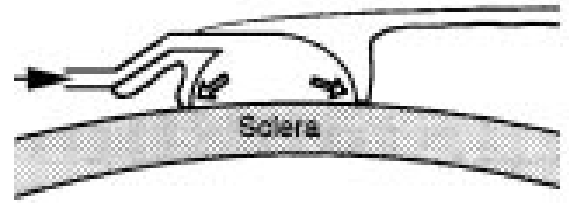

Figure 3 (A) The Baerveldt implant (scale bar $=1 \mathrm{~cm}$ ). (B) Schematic drawing of the appositional resistance mechanism included in some embodiments of the Baerveldt GDD. An annular ridge projecting from the underside of the plate element provides a temporary seal against the sclera. Absorbable sutures are used to hold the plate in apposition. As the sutures degrade, the plate element lifts clear, allowing free aqueous drainage.

complex nature of cases typically selected for implantation, the range of complications observed also reflects design and material inadequacies inherent in contemporary GDDs.

The origin of most complications can be traced to just two fundamental mechanisms-poor flow control and suboptimal material biocompatibility.

POOR FLOW CONTROL

Poor flow control after GFS leads directly to hypotony (IOP $<5 \mathrm{~mm} \mathrm{Hg}$ ), anterior chamber flattening, and choroidal detachment. Sight threatening complications, including hypotony maculopathy ${ }^{53-55}$ and delayed suprachoroidal haemorrhage ${ }^{5657}$ may result. Anterior chamber flattening is especially hazardous in the context of GDD implantation in which contact with the tube element can cause significant corneal endothelial and lens epithelial damage.

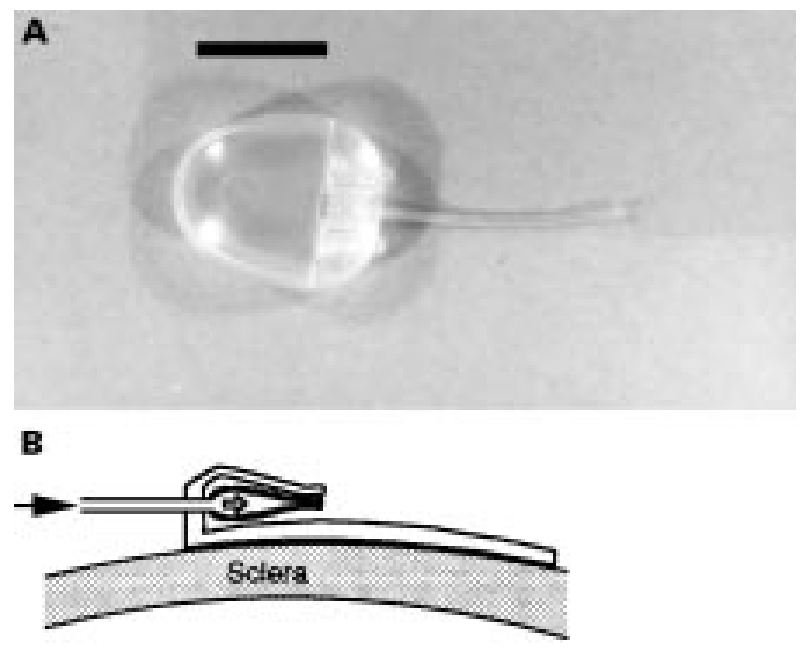

Figure 4 (A) The Ahmed glaucoma valve implant $($ scale bar $=1 \mathrm{~cm})$. (B) Schematic drawing of the resistance mechanism of the Ahmed valve. Aqueous flows (black arrow) through the tube into a chamber within the plate element. This chamber is formed by a folded over silicone membrane (black line) with its free edges forming a one way valve. Manufacturers claim that the two halves of the polypropylene body of the plate element pre-tension the valve to open at a specific level of intraocular pressure. They also claim that the venturi effect produced by the tapering trapezoidal shape of the space enclosed by the folded silicone membrane acts to improve flow regulation (increasing fluid velocity as the chamber tapers acts to reduce internal pressure proximal to the slit opening in accordance with the inverse relation between fluid velocity and pressure expressed in the Bernoulli's theorem). Neither of these claims is supported by the published experimental evidence.

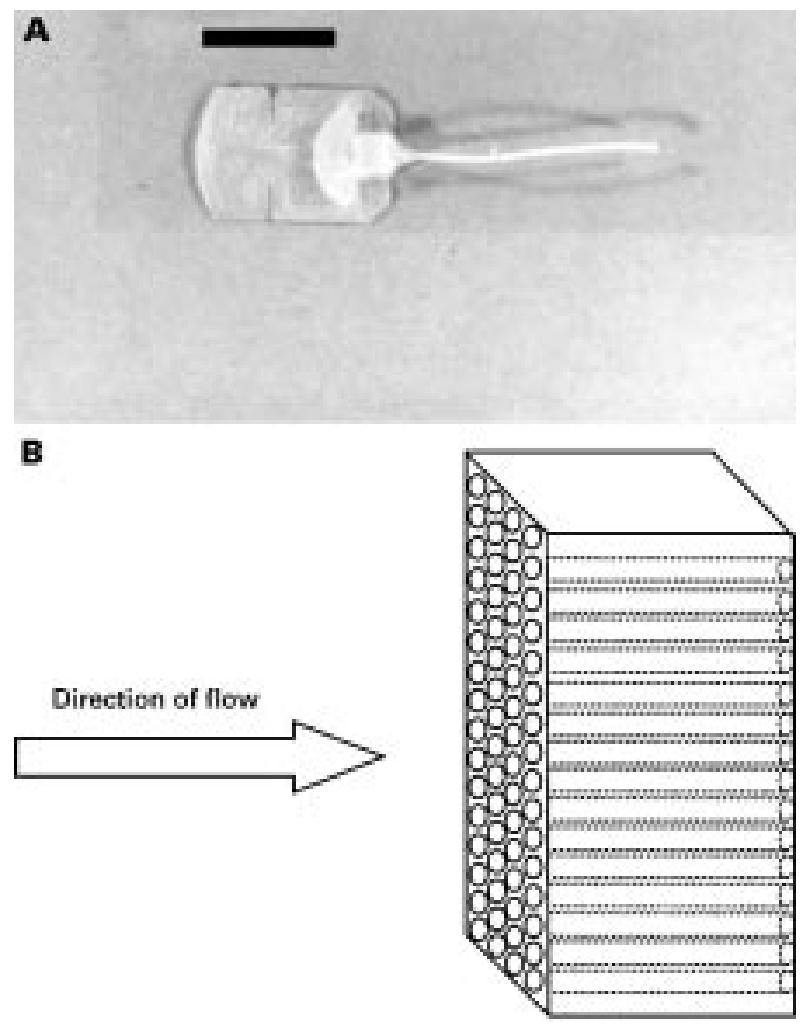

Figure 5 (A) The OptiMed implant is made up of a silicone tube with a PMMA plate. The "flow restricting" element of this device is housed within the rectangular box situated at the end of the tube within the plate (scale bar = $1 \mathrm{~cm}$ ). (B) Schematic drawing of the OptiMed implant's "flow restricting" unit which is made up of multiple microtubules providing a pressure gradient governed by Poiseuille's formula.

Poor flow control and hypotony may also compromise filtration function. The aqueous concentration of high molecular weight fibroblast stimulating proteins ${ }^{58}$ is increased in conditions of blood-aqueous barrier breakdown 
Table 3 Success rates of current GDDs

\begin{tabular}{|c|c|c|c|c|c|c|c|c|}
\hline Type & Investigator & Year & Diagnosis & $\begin{array}{l}\text { No of } \\
\text { eyes }\end{array}$ & $\begin{array}{l}\text { Follw up } \\
\text { (months) } \\
\text { mean (SD) }\end{array}$ & $\begin{array}{l}\text { Definition of } \\
\text { success }\end{array}$ & $\begin{array}{l}\text { Success } \\
\text { rate } \\
\text { without } \\
\text { medication }\end{array}$ & $\begin{array}{l}\text { Success } \\
\text { rate with } \\
\text { medications }\end{array}$ \\
\hline \multicolumn{9}{|l|}{ Molteno } \\
\hline SP and DP & Mills $^{39}$ & 1997 & Mixed (25\% neovascular) & 77 & $44+\dagger$ & $\mathrm{IOP} \leqslant 22 \mathrm{~mm} \mathrm{Hg}$ & $23 \%$ & $34 \%$ \\
\hline SP & Mermoud $^{40}$ & 1993 & Neovascular & 60 & $24.7(13.4)$ & IOP $\leqslant 21$ & $17 \%$ & $20 \%$ \\
\hline SP & Heuer $^{41}$ & 1992 & Mixed (no neovascular) & 50 & $14.9(8.9)$ & $5 \leqslant \mathrm{IOP} \leqslant 21$ & $10 \%$ & $40 \%$ \\
\hline $\mathrm{DP}$ & & & & 52 & $16.4(6.8)$ & & $12 \%$ & $63 \%$ \\
\hline SP & Minckler $^{42}$ & 1988 & Mixed ( $50 \%$ neovascular) & 90 & 17.6 & IOP $\leqslant 21$ & $7 \%$ & $40 \%$ \\
\hline \multirow[t]{3}{*}{ Ahmed } & Coleman $^{26}$ & 1995 & Mixed & 60 & $9.3+\dagger$ & IOP $<22 \dagger$ & NA & NA $(78 \%) \subseteq$ \\
\hline & Coleman $^{43}$ & 1997 & Penetrating keratoplasty $\$ \mathbb{S}$ & 31 & $16+t$ & $\mathrm{IOP}<22 \dagger^{\star \star}$ & $26 \%$ & $39 \%$ \\
\hline & Coleman $^{44}$ & 1997 & Paediatric, mixed & 24 & $16.3(11.2)$ & IOP $<22 \dagger$ & $33 \%$ & $38 \%$ \\
\hline \multirow[t]{2}{*}{ Krupin disc } & Krupin Study Group ${ }^{45}$ & 1994 & Mixed & 50 & $25.4(2.4)$ & IOP $\leqslant 19$ & $47 \%$ & $33 \%$ \\
\hline & Fellenbaum $^{24}$ & 1994 & Mixed & 25 & 13.2 & $6 \leqslant \mathrm{IOP} \leqslant 21$ & $28 \%$ & $36 \%$ \\
\hline \multicolumn{9}{|l|}{ Baerveldt } \\
\hline $\begin{array}{l}200,250,350,500 \\
\mathrm{~mm}^{2}\end{array}$ & Siegner $^{46}$ & 1995 & Mixed & 103 & $13.6(0.9)$ & $5 \leqslant \mathrm{IOP} \leqslant 22$ & $45 \%$ & $27 \%$ \\
\hline $200,350,500 \mathrm{~mm}^{2}$ & Sidoti $^{47}$ & 1995 & Neovascular & 36 & $15.7(7.2)$ & $6 \leqslant \mathrm{IOP} \leqslant 21$ & $33 \%$ & $17 \%$ \\
\hline $350 \mathrm{~mm}^{2}$ & Lloyd $^{48}$ & 1994 & Mixed & 37 & $15.5(4.8)$ & $6 \leqslant \mathrm{IOP} \leqslant 21$ & $14 \%$ & $70 \%$ \\
\hline $500 \mathrm{~mm}^{2}$ & & & & 36 & $14.1(5.4)$ & & $36 \%$ & $47 \%$ \\
\hline
\end{tabular}

Molteno SP $=$ Molteno single plate.

Molteno DP $=$ Molteno double plates.

${ }^{\star}$ With no further glaucoma surgery or devastating complication.

${ }^{\star}$ Without graft failure.

$\$$ Total success rate only.

\SConcurrent or prior.

HOr reduction of $>20 \%$ if preoperative IOP $>22 \mathrm{~mm} \mathrm{Hg}$. Data from same patients may appear in more than one of these three series.

t†Median follow up (months). Mean values not available in these reports, making direct comparison difficult.

promoted by hypotony, ${ }^{59}$ and an association between prolonged postoperative hypotony and a higher final IOP has been observed in conventional GFS. ${ }^{60} 61$

Modifications to GDDs and implantation techniques since Molteno's original device have largely been driven by attempts to minimise rates of early postoperative hypotony. Devices can be categorised into GDDs with no internal resistance mechanism, GDDs with no set internal resistance, and GDDs which aim to provide set internal flow resistance.

No resistance mechanism

Early Molteno and Baerveldt implants were simple tube and plate devices with no internal resistance mechanism.

After GFS, resistance to flow distal to the sclerostomy or GDD generally remains low until limited subconjunctival wound healing has occurred and the initially diffuse aqueous escape becomes confined within a maturing filtration bleb. Having observed frequent problems with hypotony in early single stage implantation, ${ }^{62}$ Molteno recognised that some allowance for this early period of minimal distal flow resistance would be required. A two stage procedure was initially explored, ${ }^{63}$ in which the device was implanted and allowed to encapsulate before insertion of the tube element into the anterior chamber at a second operation after 2-6 weeks. In addition to a second operation, a separate provision for initial IOP control in the intervening period was required and, while the two stage approach was successful in reducing problems with hypotony, variations of a modified single stage procedure are now widely preferred for GDDs with no internal resistance mechanism. These include ligation with an absorbable suture, ${ }^{64}$ laser suture lysis, ${ }^{65}$ and occlusion with a supramid stent which is later removed through a small conjunctival incision. ${ }^{66}$ Single stage methods seek to occlude the lumen of the tube element temporarily to allow partial encapsulation of the plate. They rely on external leakage with or without a slit incision through the subconjunctival portion of the tube proximal to the occlusion to provide initial outflow. Neither of these initial flow mechanisms is well controlled,

Table 4 Cumulative complication rates in the currently used GDDs

\begin{tabular}{|c|c|c|c|c|}
\hline Complications & $\begin{array}{l}\text { Ahmed valve } \\
(n=115) \\
\text { Coleman } 1995^{26} \\
\text { Coleman } 1997^{43} \\
\text { Coleman } 1997^{44}\end{array}$ & $\begin{array}{l}\text { Krupin valve with disc } \\
(n=75) \\
\text { Krupin Study Group } 1994^{45} \\
\text { Fellenbaum } 1994^{24}\end{array}$ & $\begin{array}{l}\text { Baerveldt implant } \\
(n=249) \\
\text { Lloyd } 1994^{48} \\
\text { Sidoti } 1995^{47} \\
\text { Smith } 1993^{51} \\
\text { Siegner } 1995^{46}\end{array}$ & $\begin{array}{l}\text { Molteno implant } \\
(n=395) \\
\text { Mills } 1996^{39} \\
\text { Minckler } 1988^{42} \\
\text { Lloyd } 1992^{52} \\
\text { Heuer } 1992^{41}\end{array}$ \\
\hline Hypotony/flat anterior chamber & $3.5 \%$ & $27 \%$ & $16.5 \%$ & $5 \%$ \\
\hline Choroidal effusion/haemorrhage & $14 \%$ & $33 \%$ & $23 \%$ & $7 \%$ \\
\hline Suprachoroidal haemorrhage & $3.5 \%$ & $1.3 \%$ & $0.8 \%$ & $0.5 \%$ \\
\hline Hyphaema & 0 & $1.3 \%$ & $11 \%$ & $4 \%$ \\
\hline Vitreous haemorrhage & $3.5 \%$ & $1.3 \%$ & $7 \%$ & $2 \%$ \\
\hline Uveitis & $1.7 \%$ & $9.3 \%$ & $3.6 \%$ & $0.5 \%$ \\
\hline Malignant glaucoma & $0.9 \%$ & $2.7 \%$ & $2 \%$ & $0.5 \%$ \\
\hline Motility problem & $3.5 \%$ & $4 \%$ & $21 \%$ & $0.3 \%$ \\
\hline Cataract & N/A & N/A & $9.9 \% \dagger$ & $12 \% \star$ \\
\hline Tube blocked & $7.8 \%$ & $11 \%$ & 10 & $6 \%$ \\
\hline Tube retraction & $5.2 \%$ & $2.7 \%$ & $2.4 \%$ & $0.8 \%$ \\
\hline Tube/plate extrusion & $4.3 \%$ & N/A & 1.2 & $0.5 \%$ \\
\hline Tube/plate erosion & 0 & $2.7 \%$ & 2 & $3 \%$ \\
\hline Corneal touch & $2.6 \%$ & N/A & $4 \%$ & $3 \%$ \\
\hline Corneal decompensation & $3.5 \%$ & $5.3 \%$ & $11.6 \%$ & $14 \%$ \\
\hline Retinal detachment & 0 & 0 & $5 \%$ & $3.5 \%$ \\
\hline Encepsulated bleb & $3.5 \%$ & $1.3 \%$ & $1.6 \%$ & N/A \\
\hline Phthisis & 0 & $1.3 \%$ & $2.4 \%$ & $4 \%$ \\
\hline \multirow{3}{*}{ Others } & $1.7 \%$ Wound leak & $1.3 \%$ Wound leak & $1.6 \%$ Wound leak & $0.3 \%$ Epiretinal membrane \\
\hline & & $1.3 \%$ Endophthalmitis & $0.4 \%$ Endophthalmitis & $0.3 \%$ Perforation \\
\hline & & $1.3 \%$ Decompression retinopathy & & \\
\hline
\end{tabular}

${ }^{\star}$ Cataract developed in 11 out of 91 phakic patients. Mean follow up more than 40 months.

tCataract developed in 7 out of 69 phakic patients. Mean follow up 14.4 months. 
and problems with either too much or too little initial aqueous escape remain frequent.

\section{No set resistance}

Later versions of the Molteno and Baerveldt GDD incorporate resistance mechanisms which depend on tissue apposition to limit flow.

The Molteno dual ridge device seeks to limit the initial drainage area by dividing the top part of the plate into two separate spaces (see Fig $1 \mathrm{~B}$ and C). Aqueous escapes directly into the channel between two concentric ridges on the plate element, but must overcome resistance associated with conjunctival tissue apposition to flow further. With later partial encapsulation of the plate element, the overlying tissue balloons clear of the inner pressure ridge, and aqueous flow into the space overlying the plate is unrestricted. ${ }^{67}$

Apposition of the "Bioseal" element of the modified Baerveldt implant to the sclera with absorbable sutures (Fig 3B) also aims to provide early flow resistance, limiting initial aqueous escape from beneath the device. ${ }^{68}$

The essential problem with both approaches is that, as with trabeculectomy, the force of tissue apposition is poorly controlled. Early flow resistance varies and initial IOP levels remain unpredictable.

\section{Set resistance}

Devices which aim to set the initial IOP level by incorporating a non-adjustable resistance mechanism include the Krupin (Fig 2B), Ahmed (Fig 4B), and OptiMed (Fig 5B) GDDs.

Independent examination of the flow characteristics for each of these devices suggests a wide divergence between observed function and manufacturers' claims for flow resistance. ${ }^{37}$ Valved devices (Ahmed and Krupin) appear not to close after initial opening in perfusion tests at physiological flow rates. ${ }^{37}$ Resistance values also vary considerably between devices from the same manufacturer, indicating deficiencies in quality control. ${ }^{69}$ Clinically, hypotony has been observed in $24 \%$ of the eyes for the Krupin GDD GD $^{4}$ and $5-29 \%$ of cases after Ahmed GDD implantation. ${ }^{43} 44$

All the commonly used devices feature a round silicone anterior chamber tube with a diameter of between 0.56 $\mathrm{mm}$ and $0.63 \mathrm{~mm}$ (Table 2). The recommended technique for insertion is through a paracentesis track created by either a 22 gauge $(0.72 \mathrm{~mm})$ or 23 gauge $(0.65$ $\mathrm{mm}$ ) hypodermic needle. Debate over the optimum needle gauge continues, ${ }^{26}$ but insertion often requires considerable manipulation. The resulting tube to paracentesis fit is often poor and uncontrolled leakage external to the tube is common.

Whether primarily the result of lack of internal flow regulation or uncontrolled extrinsic leakage, problems associated with excessive early aqueous outflow and hypotony have not been adequately addressed by current GDD designs and implantation techniques.

\section{SUBOPTIMAL TISSUE COMPATIBILITY}

Tissue compatibility refers to the ability of a synthetic material to interface with living tissues without provoking a detrimental reaction. Within the context of GDD implantation, suboptimal tissue compatibility is manifest in an array of complications including early fibrinous occlusion, corneal endothelial failure, tube migration, extrusion, and fibrous encapsulation leading to filtration failure. Key elements in the mechanism of these complications are protein adhesion and micromotion.

Elastomeric silicone (polydimethylsiloxane) remains the most commonly used material in current GDDs (Table 2).
Silicone, PMMA, and other hydrophobic polymers used in GDDs have a relatively high binding affinity for plasma and interstitial fluid proteins including albumin, IgG, and fibrinogen. These proteins are adsorbed within minutes of implantation. ${ }^{70}$ Cellular adhesion, leading to subsequent cytokine release and chronic inflammation, is mediated by elements of this protein film. ${ }^{71}$

Continuing low grade inflammation is exacerbated by micromotion, or microscopic shearing of the implant relative to the surrounding tissues. Plate elements of contemporary GDDs often impinge on the extraocular muscles, either directly or through adhesions with septal elements of the orbital tissues. This was a major problem with the original Baerveldt GDD, many had to be removed due to ocular motility problems. ${ }^{72}$ Even where this does not produce a frank motility disturbance (Table 4), it is likely that shear forces transmitted through the relatively rigid materials used in GDD construction produce significant micromotion. Rabbit experiments in which the Baerveldt GDD was fenestrated to improve fibrous tissue anchoring, reducing micromotion, demonstrated a significant reduction in fibrous encapsulation thickness compared with unfenestrated controls at explantation 6 months postoperatively. ${ }^{73}$ In addition to helping drive subconjunctival fibrosis after GDD implantation, micromotion transmitted via the tube element of contemporary GDDs to the anterior chamber may lead to continuing corneal endothelial cell loss. Superimposed on perioperative endothelial damage, this is the likely mechanism of corneal endothelial failure in association with GDDs.

Progressive fibrous encapsulation limits the filtration life of all contemporary GDDs. As with poor flow control, suboptimal tissue compatibility and the resultant low grade inflammatory drive to progressive subconjunctival fibrosis have not yet been adequately addressed.

\section{Plate surface area}

One strategy for delaying filtration failure has been to increase plate surface area. In 1981, Molteno published a series $^{74}$ of 20 patients who received one plate $\left(135 \mathrm{~mm}^{2}\right)$, two plate $\left(270 \mathrm{~mm}^{2}\right)$, or four plate $\left(540 \mathrm{~mm}^{2}\right)$ Molteno implants. Mean postoperative IOPs were significantly lower for two and four plates compared with single plate implantation, but did not differ significantly between two and four plates. A subsequent randomised controlled trial involving 132 patients showed a higher success rate in the double plate $\left(270 \mathrm{~mm}^{2}\right)$ Molteno group compared with the single plate $\left(135 \mathrm{~mm}^{2}\right)$ Molteno group. ${ }^{41}$ A similar trial comparing Baerveldt implants with two different plate areas $\left(350\right.$ and $500 \mathrm{~mm}^{2}$ ) was less clear cut. ${ }^{48}$ Although fewer medications were required for the patients with 500 $\mathrm{mm}^{2}$ implants to achieve the target IOP for success $(\leqslant 21$ $\mathrm{mm} \mathrm{Hg}$ ), some complications occurred more frequently with this larger plate size. Overall, a larger filtration area would appear to improve filtration function, ${ }^{75}$ at least in the medium term, but eventual subconjunctival fibrosis over a wider area may adversely influence the prognosis for repeat GFS.

\section{Antimetabolites}

In addition to pioneering departures in GDD design, Molteno was among the first to attempt to control subconjunctival wound healing after GFS pharmacologically. He used steroids, fluphenamic acid and colchicine, systemically. ${ }^{63}$ Although filtration function appeared to improve, systemic side effects and uncertain benefits led to the abandonment of this regime. ${ }^{42}$ Successful modulation of fibroblast function with locally applied antimetabolite drugs followed, however, ${ }^{76}$ and the use of 5 -fluorouracil and mitomycin 
C in conventional GFS has become widespread over the last decade.

In a rabbit study using Baerveldt implants with and without mitomycin C, Prata et $a l^{78}$ were able to show a consistently lower IOP in the mitomycin C treated eyes. The difference remained statistically significant for up to 10 weeks postoperatively. Early clinical data have been less easy to interpret. A series of 21 patients who underwent double plate Molteno tube implantation with adjunctive intraoperative mitomycin $\mathrm{C}$ had a higher success rate (IOP $\leqslant 21 \mathrm{~mm} \mathrm{Hg})$ at 12 months than 18 historic controls $(68 \%$ v $17 \%)^{79}$; but the success rate of only $17 \%$ in the control group was unusually low (Table 3). In another series of 21 patients (no controls) using intraoperative mitomycin C and a modified Molteno implant, the success rate (IOP $\leqslant 21 \mathrm{~mm} \mathrm{Hg}$ ) was $76.2 \%$ after a mean follow up of 9.4 (SD 6.4) months. ${ }^{80}$ The profile of major complications in this group, including tube or plate erosion (14\%) and late hypotony $(9.5 \%)$, would suggest that problems such as thin bleb, hypotony maculopathy, and late endophthalmitis observed with mitomycin $\mathrm{C}$ in the context of conventional GFS may apply to GDD surgery.

\section{Current indications}

High complication rates and the likelihood of filtration failure within 5 years have confined GDD surgery to situations in which trabeculectomy is unlikely to succeed. ${ }^{36}$ Improved filtration performance in trabeculectomy with adjunctive antimetabolite treatment for cases at a high risk of failure has relegated GDD surgery still further, and the position relative to other treatment modalities, (trabeculectomy/mitomycin C or contemporary cycloablation techniques) has not been clearly defined by clinical trials.

\section{The future}

While the post-antimetabolite era of GFS may have presaged a downturn in the use of contemporary GDDs, it also heralds an opportunity to deconstruct some dated design concepts and move forward. For example, the rational basis for using a plate element to physically maintain a drainage reservoir might be questioned if subconjunctival fibrosis could be controlled pharmacologically. ${ }^{81}$ A large surface area of relatively rigid foreign material may simply exacerbate the inflammatory stimulus to progressive fibrosis. Realising this, a number of investigators are currently re-exploring anterior GDDs (trans-scleral implants with no plate element). ${ }^{30}{ }^{31}$ Clinical results are not available yet, but success will depend on a marriage of design and biomaterials improvements with well controlled pharmacological modulation of wound healing.

Recent advances in ocular biomaterials technology ${ }^{82} 83$ offer the prospect of implanting biologically inert GDDs with rigidity and biointegration characteristics designed to eliminate micromotion. These new biomaterials may greatly enhance filtration longevity, and if flow resistance and extrinsic leakage can also be controlled, there is no reason in principle why GDDs might not be used in routine GFS.

The premise here is that accurate control over flow resistance can be reproduced more easily in an implant than in the tissues themselves. Flow resistance in trabeculectomy depends on suture tension and, where suture lysis/release techniques are used, suture positioning. These factors are subjectively controlled and early postoperative hypotony remains common. ${ }^{76}{ }^{84}$ Poor flow control has also been a particular problem for laser sclerostomy techniques. ${ }^{85}$ With current laser delivery systems, sclerostomy dimensions vary initially, and are later modified by wound healing to a variable extent. In contrast, submicrometre accuracy is possible for key dimensions in implant manufacture, and GFS without hypotony is a realistic aim.

To gain a wider acceptance, development of the next generation of GDDs must be informed by improved flow performance and biocompatibility testing. Inclusion criteria and outcome measures for clinical trials should also be better defined.

The current standing of GDDs is in some ways analogous to that of intraocular lenses in the early 1970s, with frequent complications attributable to design and material inadequacies. Just as improved intraocular lenses have revolutionised cataract surgery in the recent past, new materials and design departures may transform filtration surgery with GDDs in the near future.

We were supported in part by the Department of Health and the Department of Trade and Industry.

K S LIM

Institute of Ophthalmology, London and University of Brighton, Brighton

B D S ALLAN

Moorfields Eye Hospital, London

A W LLOYD

University of Brighton, Brighton

A MUIR

Biocompatibles Ltd, Farnham, Hants

P T KHAW

Institute of Ophthalmology, London and Moorfields Eye Hospital, London

Correspondence to: Mr K S Lim, Wound Healing Research Unit, Department of Pathology, Institute of Ophthalmology, Bath Street, London EC1V 9EL.

1 Jay JL, Allan D. The benefit of early trabeculectomy versus conventional management in primary open angle glaucoma relative to the severity of the disease. Eye 1989;3:528-35.

2 Migdal CS. Rational choice of therapy in established primary open angle glaucoma. Eye 1992;6:346-7.

3 Rollett M, Moreau M. Traitement de hypopyon par le drainage capillary de la chambre anterieure. Rev Gen Ophtalmol 1906;25:481-9.

4 Rollett M, Moreau M. Le drainage au crin de la chambre anterieure contre 1'hypertonie et la douleur. Rev Gen Ophtalmol 1907;26:289-92.

5 Lee P-F, Wong W-T. Aqueous-venous shunt for glaucoma: report on 15 cases. Ann Ophthalmol 1974;6:1083-8.

6 Mascati NT. A new surgical approach for the control of a class of glaucomas. Int Surg 1967;47:10-15.

7 Zorab A. The reduction of tension in chronic glaucoma. Ophthalmoscope 1912;10:258-61.

8 Stefansson J. An operation for glaucoma. Am f Ophthalmol 1925;8:681-93.

9 Bick MW. Use of tantalum for ocular drainage. Arch Ophthalmol Bick MW. Use
1949;42:373-88.

10 Muldoon WE, Ripple PH, Wilder HC. Platinum implant in glaucoma surgery. Arch Ophthalmol 1951;45:666-72.

11 Row H. Operation to control glaucoma: preliminary report. Arch Ophthalmol 1934;12:325-9.

12 Trancosco MU. Use of tantalum implants for inducing a permanent hypotony in rabbits' eye. Am $\mathcal{F}$ Ophthalmol 1949;32:499-508.

13 Gibson G. Transcleral lacrimal canaliculus transplants. Trans Am Ophthalmol Soc 1942;40:499-515.

14 Losche W. Vorschlage zur Verbesserung der Zyklodialyse. Klin Monatsbl Augenheilkd 1952;121:715-16.

15 Bietti GB. The present state of the use of plastics in eye surgery. Acta Ophthalmol 1955;33:337-70.

16 La Rocca V. Int Cong Ophthalmol (Brussels) 1958.

17 Ellis RA. Reduction of intraocular pressure using plastics in surgery. Am $\mathcal{F}$ Ophthalmol 1960;68:879-83.

18 Molteno ACB. New implant for drainage in glaucoma. Animal trial. $\mathrm{Br} f$ Ophthalmol 1969;53:161-8.

19 Krupin T, Podos SM, Becker B, et al. Valve implants in filtering surgery. A preliminary report. Am f Ophthalmol 1976;81:232-5.

20 Honrubia FM, Grijalbo MP, Gomez ML, et al. Surgical treatment of neovascular glaucoma. Trans Ophthalmol Soc UK 1979;99:89-91.

21 Schocket SS, Lakhanpal V, Richards RD. Anterior chamber tube shunt to an encircling band in the treatment of neovascular glaucoma. Ophthalmology 1982;89:1188-94.

22 White TC. A new implantable ocular pressure relief device. A preliminary report. Glaucoma 1985;7:289-94.

23 Joseph NJ, Sherwood MB, Trantas G, et al. A one piece drainage system for glaucoma surgery. Trans Ophthalmol Soc UK 1986;105:657-64.

24 Fellenbaum PS, Almeida AR, Minckler DS, et al. Krupin disk implantation for complicated glaucoma. Ophthalmology 1994;101:1178-82.

25 Lloyd MA, Baerveldt G, Heuer DK, et al. The Baerveldt glaucoma implant-long-term histologic studies in rabbits and clinical experience in humans. Invest Ophthalmol Vis Sci 1991;746 (abstract). 
26 Coleman AL, Hill R, Wilson MR, et al. Initial clinical experience with the Ahmed glaucoma valve implant. Am f Ophthalmol 1995;120:23-31.

$27 \mathrm{Kim}$ DD, Menmen JE Spontaneous disengagement of the OptiMed implant. Arch Ophthalmol 1996;114:1420-1.

28 Smith SG, Galanis JC. One-year results of the intrascleral glaucoma implant. F Cataract Refract Surg 1995;21:453-6.

29 Pandya AD. Experimental evaluation of a hydroxyapatite reservoir tube shunt in rabbits. Ophthalmic Surg Laser 1996;27:308-14.

30 Glovinsky Y, Belkin M. Evaluation of the "G-Plant" glaucoma shunt in rabbit eyes. Invest Ophthalmol Vis Sci 1997;38:53.

31 Helies P, Savoldelli M, Legeais JM, et al. Artificial MESHWORK (MESH). Clinical and histological study in the rabbit with a six months follow up. Invest Ophthalmol Vis Sci 1997;38:1246.

32 Miller MH, Grierson I, Unger WI, et al. Wound healing in an animal model of glaucoma fistulizing surgery in the rabbit. Ophthalmic Surg 1989;20:3507 .

33 Jampel HD, Leong KW, Dunkelburger GR, et al. Glaucoma filtration surgery in monkeys using 5-fluorouridine in polyanhydride disks. Arch surgery in monkeys using 5-
Ophthalmol 1990;108:430-5.

34 Cairns JE. Trabeculectomy. Preliminary report of a new methods. $A m \mathcal{F}$ Ophthalmol 1968;66:673-9.

35 Molteno ACB, Strachan J, Ancker E. Long tube implants in the management of glaucoma. S Afr Med 1976;50:1062-6.

36 Melamed S. Molteno implant surgery in refractory glaucoma. Surv Ophthalmol 1990;34:441-8.

37 Prata JA, Mermoud A, LaBree L, et al. In vitro and in vivo flow characteristics of glaucoma drainage implants. Ophthalmology 1995;102:894-904

38 Krawczyk CH. Glaucoma drainage devices and the FDA. Ophthalmology 1995;102:1581-2

39 Mills RP, Reynolds A, Emond MJ, et al. Long-term survival of Molteno glaucoma drainage devices. Ophthalmology 1996;103:299-305.

40 Mermoud A, Salmon JF, Alexander P, et al. Molteno tube implantation for neovascular glaucoma. Long term results and factors influencing the outcome. Ophthalmology 1993;100:897-902

41 Heuer DK, Lloyd MA, Abrams DA, et al. Which is better? One or two? A randomized clinical trial of single plate versus double plate Molteno implantation for glaucomas in aphakia and pseudophakia. Ophthalmology 1992;99:1512-19.

42 Minckler DS, Heuer DK, Hasty B, et al. Clinical experience with the single plate Molteno implant in complicated glaucomas. Ophthalmology 1988;95: $1181-8$.

43 Coleman AL, Mondino BJ, et al. Clinical experience with the Ahmed glaucoma valve implant in eyes with prior or concurrent penetrating keratoplasties. Am f Ophthalmol. 1997;123.54-61.

44 Coleman AL, Smyth RJ, Wilson MR, et al. Initial clinical experience with the Ahmed glaucoma valve implant in paediatrics patients. Arch Ophthalmol 1997;115:186-91

45 Krupin Eye Valve Filtering Surgery Study Group. Krupin eye valve with disk for filtration surgery. Ophthalmology 1994;101:651-8.

46 Siegner SW, Netland PA, Urban RC, et al. Clinical experience with the Baerveldt glaucoma drainage implant. Ophthalmology 1995;102:1298-307.

47 Sidoti PA, Dunphy TR, Baerveldt G, et al. Experience with the Baerveldt glaucoma implant in treating neovascular glaucoma. Ophthalmology 1995;102:1107-18.

48 Lloyd MA, Baerveldt G, Fellenbaum PS, et al. Intermediate-term results of a randomized clinical trial of the 350 versus the $500 \mathrm{~mm}^{2}$ Baerveldt implant. Ophthalmology 1994;101:1456-63.

49 Grant WM, Burke JF. Why do some people go blind from glaucoma? Ophthalmology 1982;89:991-8.

50 Mao LK, Stewart WC, Shields MB. Correlation between intraocular pressure control and progressive glaucomatous damage in primary open angle glaucoma. Am f Ophthalmol 1991;111:51-60.

51 Smith SL, Starita RJ, Fellman RL, et al. Early clinical experience with the Baerveldt $350 \mathrm{~mm}^{2}$ glaucoma implant and associated extraocular muscle imbalance. Ophthalmology 1993;100:914-18.

52 Lloyd MA, Sedlak T, Heuer DK, et al. Clinical experience with the single plate Molteno implant in complicated glaucomas: update of a pilot study. Ophthalmology 1992;99:679-87.

53 Costa VP, Smith M, Spaeth GL, et al. Loss of visual acuity after trabeculectomy. Ophthalmology 1993;100:599-612.

54 Stamper RL, McMenemy MG, Lieberman MF. Hypotonous maculopathy after trabeculectomy with subconjunctival 5-fluorouracil. Am f Ophthalmol 1992;114:544-53.

55 Cheung JC, Wright MW, Murali S, et al. Intermediate-term outcome of variable dose mitomycin c filtering surgery. Ophthalmology 1997;104:1439.
56 Paysee E, Lee PP, Lloyd MA, et al. Suprachoroidal haemorrhage after Molteno implantation. J Glaucoma 1996;5:170-5.

57 Gressel MG, Parrish RK, Heuer DK. Delayed non-expulsive suprachoroidal haemorrhage. Arch Ophthalmol 1984;102:1257-61.

58 Joseph JP, Grierson I, Hitchings RA. Partial characterization of the fibroblast chemotactic constituents of human aqueous humour. Int Ophthalmol 1989;13:125-30.

59 Liebmann JM, Sokol J, Ritch R. Management of chronic hypotony after glaucoma filtration surgery. F Glaucoma 1996;5:210-20.

60 Migdal CS, Hitchings RA. Morbidity following prolonged hypotony after trabeculectomy. Ophthalmic Surg 1988;19:865-7.

61 Blondeau P, Phelps CD. Trabeculectomy vs thermosclerostomy: a randomized prospective trial. Arch Ophthalmol 1981;99:810-16.

62 Molteno ACB, Von Rooyen MMB, Bartholomew RS. Implants for draining neovascular glaucoma. Br f Ophthalmol 1977;61:120-5.

63 Molteno ACB. The use of drainage implants in resistant cases of glaucoma. Trans Ophthalmol Soc NZ 1983;35:94-7.

64 Molteno CB, Polkinghorne J, Bowbyes A. The vicryl tie technique for inserting a draining implant in the treatment of secondary glaucoma. Aust NZ7 Ophthalmol 1986;14:343-54.

65 Price FW, Whitson WE. Polypropylene ligatures as a means of controlling intraocular pressure with Molteno implants. Ophthalmic Surg 1989;20:7813

66 Egbert PR, Liebert MF. Internal suture occlusion of the Molteno glaucoma implant for the prevention of postoperative hypotony. Ophthalmic Surg 1989;20:53-6

67 Freeman J. Clinical experience with the Molteno dual chamber single plate implant. Ophthalmic Surg 1992;23:238-41.

68 Baerveldt G, Chou JS, Longren B. Comparison of the Baerveldt glaucoma implant with bioseal to the Baerveldt implant in rabbits. Invest Ophthalmol Vis Sci 1997;38:52.

69 Porter JM, Krawczyk CH, Carey RF. In vitro flow testing of glaucoma drainage devices. Ophthalmology 1997;104:1701-7.

70 Pitt WG, Park K, Cooper SL. Sequential protein adsorption and thrombus deposition on polymeric biomaterials. F Colloid Interface Sci 1986;111:34362 .

71 Tang L, Eaton JW. Fibrin(ogen) mediates acute inflammatory responses to biomaterials. f Exp Med 1993;178:2147-56.

72 Smith SL, Starita RJ, Fellman RL, et al. Early clinical experience with Baerveldt $350 \mathrm{~mm}^{2}$ glaucoma implant and associated extraocular muscle imbalance. Ophthalmology 1993;100:914-18.

73 Jacob-Labarre JT, McKinnon SJ, Tanji T. Biocompatibility response to modified Baerveldt glaucoma drains. Invest Ophthalmol Vis Sci 1996; 37(Suppl): 1164

74 Molteno ACB. The optimal design of drainage implants for glaucoma. Trans Ophthalmol Soc NZ 1981;33:39-41.

75 Minckler DS, Shammas A, Wilcox M, et al. Experimental studies of aqueous filtration using the Molteno implant. Trans Am Ophthalmol Soc 1987;84: 368-92.

76 Fluorouracil Filtering Surgery Study Group. One year follow-up. Am f Ophthalmol 1989;108:625-35.

77 Skuta GL, Beeson CC, Higginbotham EJ, et al. Intraoperative mitomycin versus postoperative 5-fluorouracil in high-risk glaucoma filtering surgery. Ophthalmology 1992;99:438-44.

78 Prata JA, Minckler DS, Mermoud A, et al. Effects of intraoperative mitomycin-C on the function of Baerveldt glaucoma implants in rabbits. $\mathcal{F}$ Glaucoma 1996;5:29-38.

79 Perkins TW, Cardakli F, Eisele JR, et al. Adjunctive mitomycin C in Molteno implant surgery. Ophthalmology 1995;102:91-7.

80 Susanna R, Nicolela MT, Takahashi WY. Mitomycin C as adjunctive therapy with glaucoma implant surgery. Ophthalmic Surg 1994;25:458-62.

81 Kee C, Youn DH. Experimental designed glaucoma implant surgery with mitomycin-C in rabbits. Korean f Ophthalmol 1995;9:89-95.

82 Ikada Y. Surface modification of polymers for medical applications. Biomaterials 1994;15:725-36.

83 Hall B, Bird R, Kojima M, et al. Biomembranes as models for polymer surfaces. Biomaterials 1989;10:219-24.

84 Block MDW, Greve EL, Dunnebier EA. Scleral flap sutures and the development of flat or shallow anterior chambers after trabeculectomy. Invest Ophthalmol Vis Sci 1992;33(Suppl):2898.

85 Allan BDS, van Saarloos PP, Cooper RL, et al. Excimer laser sclerostomy in pseudophakic patients with advanced open angle glaucoma. $\mathrm{Br} \mathcal{F}$ Ophthalmol 1994;78:199-205. 